\title{
MOBILE LEARNING FOR PHYSICAL EDUCATION STUDENTS IN VIETNAM: PROMISES AND CHALLENGES
}

\author{
Nguyen The Luong ${ }^{1}$, \\ Nguyen $\mathrm{Ngoc} \mathrm{Vu}^{2}$, \\ Nguyen Thi Hong Lien ${ }^{3 i}$ \\ ${ }^{1}$ HCMC University of Physical Education \& Sports, \\ 639 Nguyen Trai District 5, Ho Chi Minh city, 749000, \\ Vietnam \\ 2,3 Hoa Sen University, \\ 8 Nguyen Van Trang District 1 , \\ Ho Chi Minh city, 71000, \\ Vietnam
}

\begin{abstract}
:
The rise in mobile learning has seen an impressive increase as smartphones and tablets have increased in popularity in recent years. The cheap, easy access to these devices for students contributes to the need for use for educational and learning purposes. This trend is no exception for physical education. This study surveyed 125 physical education students in 4 badminton classes from 2018 to 2020 to evaluate their readiness for mobile learning in terms of hardware devices, technology skills, learning styles, and habits. Data coming from questionnaires in the courses and server logs of a mobile learning system show that the majority of physical education students in the study are ready for mobile learning despite some challenges regarding internet infrastructure and lack of formal online learning skills training.
\end{abstract}

Keywords: mobile learning, badminton training, learning styles, physical education

\section{Behavioural treatments and token economy}

The quick advance of technology in recent years has brought about the rapid development of mobile devices in many countries, including Vietnam. The quality of these mobile devices keeps improving while their cost is increasingly lower. Together with a widespread broadband internet connection, these factors have affected language learners' learning styles and teaching methods in environments where these mobile technologies are used. A lot of work has been dedicated to explaining how mobile

\footnotetext{
i Correspondence: email luongtn@upes.edu.vn, vu.nguyenngoc@hoasen.edu.vn,
} lien.nguyenthihong@hoasen.edu.vn 
technology can help both conventional and creative ways of teaching and learning, demonstrating how mobile learning can be extended across a broad spectrum of learning activities (Borba et al., 2016; Langbeheim \& Levy, 2019; Vu \& Thu, 2015; Yusuf et al., 2018) and highlighting the emerging issues. In recent years, there have been many pieces of research exploring the effectiveness of mobile-assisted language learning (MALL) in different contexts, for instance, using mobile phones to deliver physical education course materials (Huy et al., 2020; Vu, 2016a), and using VR materials to support students' practice in badminton sessions. This paper reviews mobile assisted language learning literature and tries to deal with the following questions:

- How ready are physical education students in Vietnam ready for mobile learning?

- What are students' perceptions of mobile learning for badminton training?

\section{Literature on mobile-assisted learning}

\subsection{What is mobile learning?}

Mobile learning is developing rapidly beyond the expectation of ICT experts. In the past, mobile learning has often been defined in terms of mobile technologies (Chao, 2019; Linh $\& \mathrm{Vu}, 2021$; Sun et al., 2017). However, recent literature on mobile learning emphasized the mobility of learners. The widespread ownership of mobile and wireless devices like iPhones, iPads, tablets, phablets, etc. allows learners to participate more actively in learning resources and activities that are related to their personal needs. While some argued that mobile learning involved the use of any portable devices like cassette players, DVD players, TV, portable LCD projectors, mobile learning is often used to refer to more recent technologies. Typically, mobile learning is defined based on two essential aspects: it allows learning to happen anytime, and it mainly uses handheld or palmtop devices. Within this article, mobile learning refers to learning that is made possible by the use of mobile devices that allow users to learn at any time and at their convenience.

\subsection{Mobile assisted learning classification}

According to $\mathrm{Vu}$ (2016b), mobile learning can be classified into many categories as technology-driven mobile learning; connected classroom learning; the informal, personalized, situated mobile learning; mobile training; performance support, the remote, rural, or development mobile learning; inclusion, assistant and diversity, and large-scale implementation. Obviously, mobile learning belongs to diversified categories, which bring many benefits in learning support in general, and in physical education in particular. Besides, the two major sectors contributing to mobile learning include advances in mobile digital technology and technological advances making mobile devices more available and affordable to everyone (Suartama et al., 2019).

According to Manzoor (2018), mobile learning content can be accessed across a wide variety of platforms. These platforms powered by increasingly better hardware devices which controlled all aspects of social life like business, work, and leisure, has become more personalized, user-centered, mobile and ubiquitous (Sun et al., 2017). Among them, smartphones and other handheld devices using WIFI used to access the 
Internet easily are most popular. Many handheld mobile digitals now have their own storage capabilities and wireless access to the Internet. Portable storage like flash drives and CD's which has also been reduced in size and upgraded in capacity is another category of devices for mobile learning. Last but not least, wireless mobile devices operating thanks to the use of a network interface card (NIC) to connect to a network and enable wireless data and voice communications are also investigated for their mobile learning potential (Feng et al., 2019; Vu et al., 2020).

Since there are still different understandings of what types of mobile learning are suitable for physical education and training, we suggest a learner-centered classification. Accordingly, there are two major types of mobile learning activities for physical education students: multimedia content and interaction tools for students like forums, wikis or glossaries.

\subsection{The role of the learner and the teacher in mobile learning}

Most theories of language teaching now are built on the assumption that learning happens in a classroom environment mediated by a qualified teacher. Therefore, these theories fail to include the distinctiveness of mobile learning. An acceptable mobile learning pedagogy must take into account the considerable amount of learning that happens outside the classroom and actively led by the learners. To look at how mobile devices may be used to better help teaching and learning, one needs to be aware of its strength. It is the opportunity to deliver personal, spontaneous, ubiquitous, and flexible learning in all ways that are meaningful. According to Feng et al. (2019), mobile learning offers and enhances an improved cognitive environment where learners can engage with their teachers, their course materials, their physical and virtual environment. The mobile learning pedagogy from this viewpoint is mainly student-centered. In this pedagogical style, students are assumed to arrive with some information before they reach the classroom and thus should be encouraged to construct their meaning by interacting as much as possible, reading, writing, and reflecting on the content. Doumanis et al. (2019) claim that when collaborating with each other, students in online courses will be encouraged to share their work, which will also allow them to conceptualize and augment their understandings. Mobile learning can facilitate this kind of collaboration by building groups of learners who are committed to the common goal.

Typically, in a mobile learning environment, the learners should be able to:

- Decide the learning methods that work best for them with their own devices

- Determine what they want to learn based on a wide selection of course materials

- Form their own learning groups by using social networks or collaboration tools like Facebook, Twitter, YouTube, Google Docs, Wiki, Blog etc.

- Take the initiative to interact with their instructor and their peers.

According to Hung et al. (2018), in traditional classrooms, the teacher's role was to be an expert giving lectures to learners who are considered empty minds that need filling. With the advance of Web 2.0 and social networks, learners have many media channels at their disposal to present their own ideas. In such a setting, the role of the teacher shifts from the presenter of expert knowledge to the moderator of opinions. Linh and $\mathrm{Vu}(2019)$ 
claims that this role is much more challenging as teachers need to accept different opinions and positions and guide the process of knowledge selection and acquisition. With mobile learning, it is even more challenging for the teachers as learning processes are no longer defined settings. Teaching and learning no longer happen only in the classroom or the lecture hall on the campus. Teaching and learning can now occur in the study rooms in students' homes, in the train they are traveling on or in public places they meet other people. Within this context, the role of the teacher slowly shifts towards being a consultant (Retnaningrum, 2019). Teachers now need to find out what learners are interested in, relate these interests to the learning goals, and provide learning opportunities appropriate for the learners' specific conditions.

\section{Method}

\subsection{Participants and procedure}

The badminton physical education students in this study used the m-learning system based on Moodle since September 2018. The researchers built up to four courses in the system for the pre-service badminton physical education classes they were in charge of. The sample of courses for this study included three classes with 125 students, 30,4\% of whom were females $(n=38)$. Most of the learners were from 18 to 22 years of age. Generally, the learners were well aware of their grade point average and therefore sought to perform as high as they could in the courses.

The courses were 15 weeks long. Every week, the teaching schedule required two class hours of face to face meetings in which often students were encouraged to log into the mobile learning platform and do some learning activities. However, most of these activities were created specifically for students to do on their own at home, and not in a classroom. A questionnaire was given to students inside the mobile learning system right in the first week. A portion of the course time was also spent to ensure that the students recognized that performing the same tasks with the mobile learning system was somewhat different from conventional learning. The learners were requested to access all learning materials uploaded, join discussion forums and complete the learning activities generated by the end of each learning session.

It was assumed that desktop computers were still the overwhelmingly major technology possessed by students besides mobile devices. Therefore, students were allowed to access the learning materials on both regular desktops and mobile phones. They were told to switch between platforms as they desired, and they could even begin the lesson on one platform and then complete it on the other without any disadvantage. Students were also told in advance that data would be collected and used for research and system upgrading, but their privacy would be protected.

\subsection{System description}

The main technology used in this research was a learning management system built from Moodle that is responsive to mobile screens. This platform had a different interface for desktop screens and mobile devices, and it could automatically identify the user 
computer to switch to the right interface. Both of these systems both have the same database, so students can learn on one device and review those activities on the other.

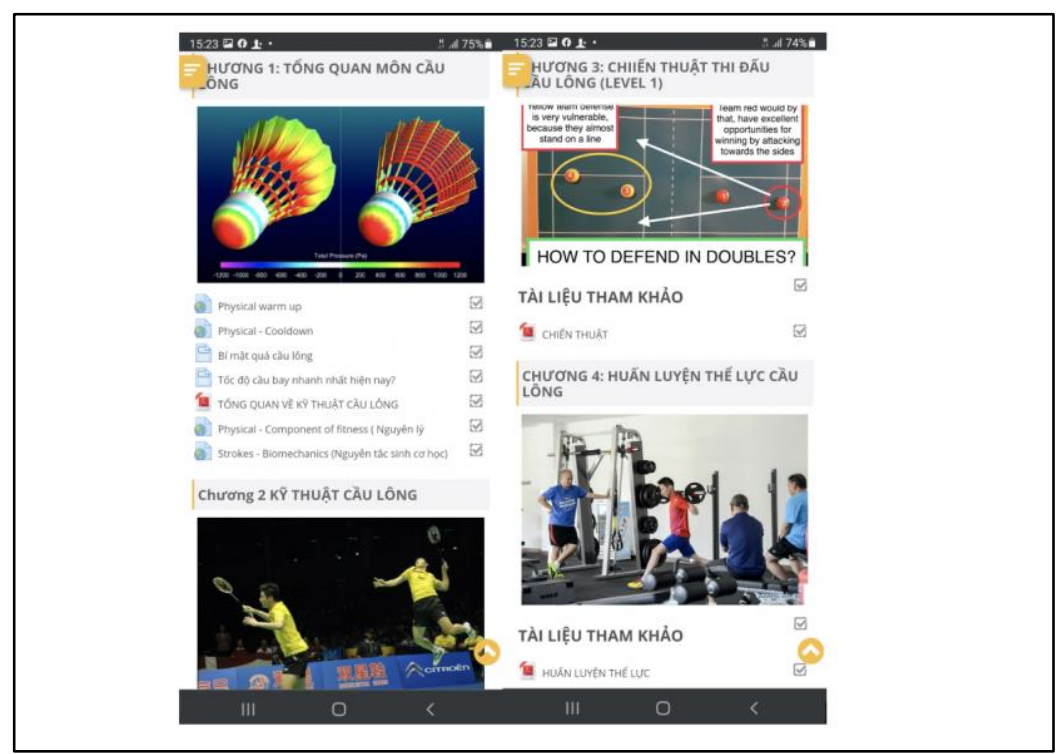

Figure 1: Snapshots of the badminton training course on mobile phone

The provided mobile learning platform offered a variety of content that could be used to reinforce learning among students. With this platform, the participants in the study used a range of learning activities such as: discussion boards, video guides embedded on YouTube, glossaries, articles, blogs, quizzes, and resource related lists. A part of the platform was also updated to incorporate the latest innovations that made it easier to deliver discussion topics online. The majority of the learning experiences were structured to be more personalized and help students to acquire the requisite skills that are described in the course outcomes.

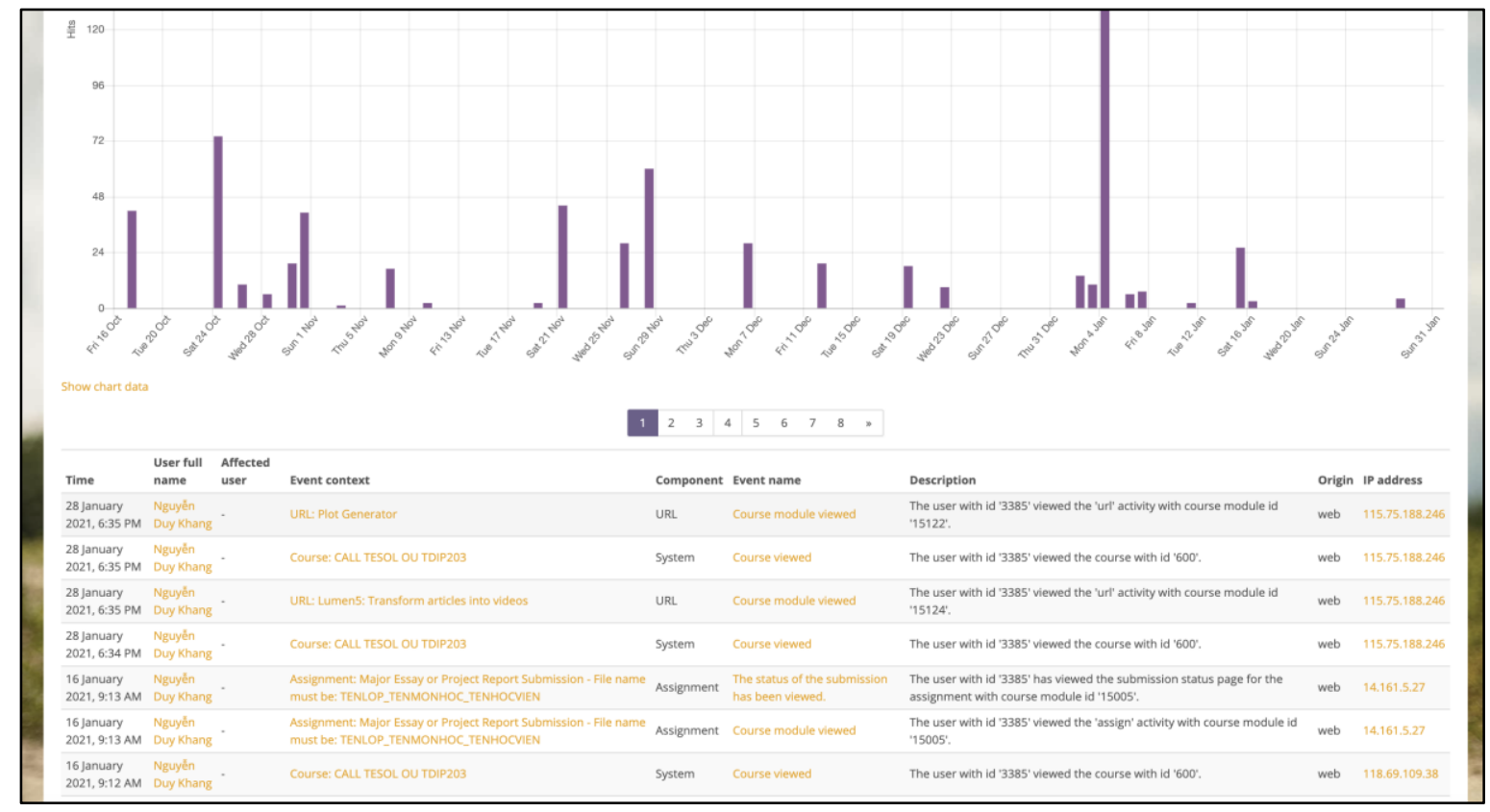

Figure 1: A sample report for student's activities in the system 
Additionally, the system has a report feature so that a teacher can keep track of students' online activities and assess them. Through this course outline report or complete course report tool, the teacher will see all the activities fetched from the server logs, including what students posted to the forum, how well they did in the quizzes, how many times they viewed a learning resource. An example of this report is demonstrated in Figure 2.

\subsection{Data collection}

The data were collected through detailed server logs automatically kept by the system. In addition, a survey was administered at the beginning and the end of the course. The server logs kept a record of access time, student's action, the learning activity student worked on, the time the learning activity was started and ended, the number of attempts together with a variety of other administration information. For the sake of system performance, the server logs were kept for only six months before they were automatically removed. To avoid accidental data loss, the course contents together with server logs were backed up every week.

The surveys were given in the form of anonymous questionnaires at the beginning and at the end of the course. These surveys investigated the mobile learners concerning their background information, the type of devices they used to access course material, their preferences when accessing content, their understanding of the advantages and disadvantages of mobile learning, their learning style, their attitudes to mobile learning, and their readiness for mobile learning. Technical readiness data was gathered using a Likert scale ranging from "Never or almost never true of me" to "Always or almost always true of me". Data about learning styles and habits were gathered in a similar way. Besides, the questionnaires also included open ended questions to examine learners' views of the benefits and disadvantages of mobile learning. The end of course survey asked students about what they liked and disliked about the course, the effectiveness of the system, and the learning activities they enjoyed. Likert scale items ranging from "Not at all" to "Very much" were used to measure students' enjoyment for specific learning tasks. Likewise, students' perception about the effectiveness and the future of mobile learning was measured using a Likert scale ranging from "Strongly agree" to "Strongly disagree."

\section{Results and discussion}

\subsection{Students' devices and technical readiness for mobile learning}

Out of 125 learners, the total number of first surveys obtained was 107 . (85,6 \%). The majority of students (85\%) used netbooks or laptops to access course material, followed by $79 \%$ of students using a smartphone, as shown in Chart 1 . In this research, smartphones are described as mobile phones with much more advanced hardware and capabilities such as the iPhone, Samsung Galaxy, HTC, etc. An additional 14\% of the respondents surveyed reported that they have used tablets or e-book readers for course work. All learners were equipped with devices to access materials from the mobile learning system, according to the survey. They all had a decent Internet connection at 
home as well. As the learning system was designed to operate on both laptops and smartphones, the ability to engage in learning activities in the system was not impacted by the types of devices. Students were also equipped for mobile learning in terms of hardware devices and internet access. The learners were also familiar with the usage of internet resources such as forums for conversation, voice chat, text chat, blogs. At the speed of 30 words per minute, most of them could type comfortably.

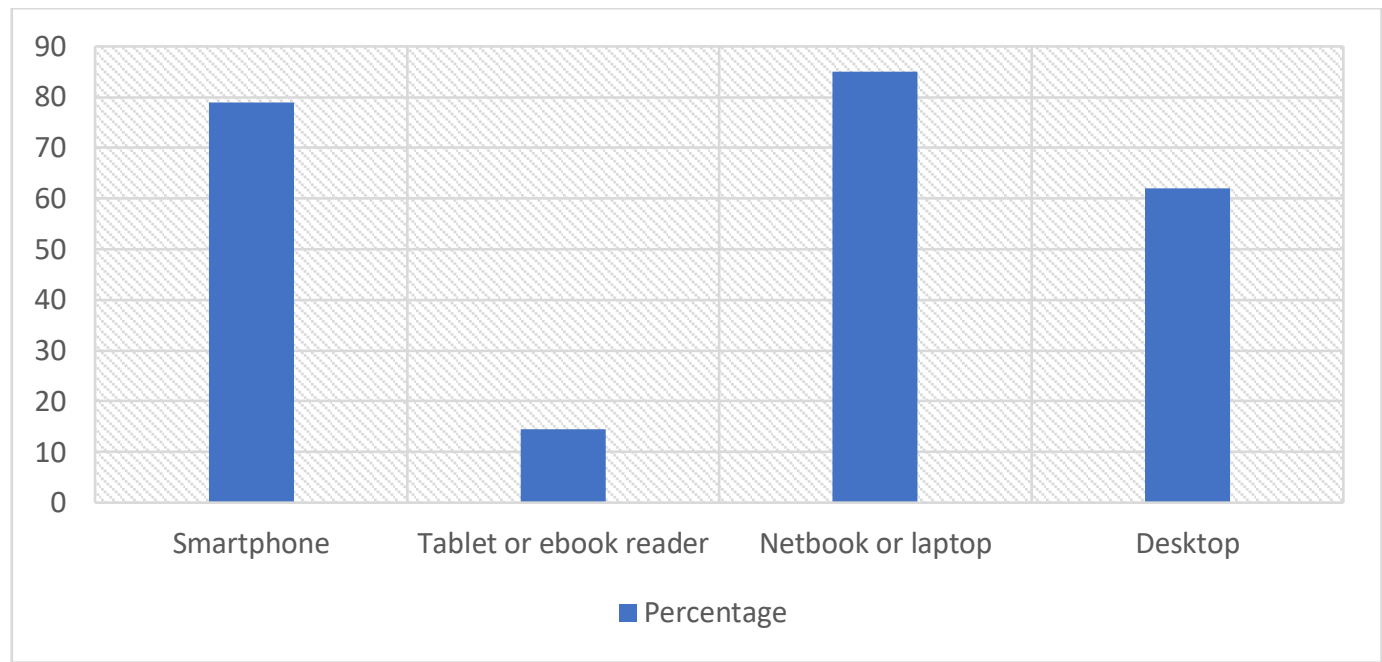

Chart 1: Devices students used to access course contents $(n=107)$

In another survey question, we asked how students routinely used mobile devices for a wide range of purposes as shown in graph 2. After doing the face to face training, mobile devices were mostly used for recreation (4.2 for listening to music, 4.0 for send/receive SMS). Students didn't use their mobile devices much to study on a regular basis with using learning apps scores only 3.2, the lowest score of all purposes. The primary purpose of a smartphone scored only 4.0, indicating that smartphones are used for a range of uses other than making phone calls. These data show that students use their smartphones to do various activities, including learning support with or without the help of a mobile learning system in their university.

While most students are prepared for their class activities with working cell phones or laptops, most of them complained about the internet connection, as in this reaction: "Internet connection is slow. Often, since my internet connection decreases, I cannot reach the voice chat. It is sometimes really complicated to watch tutorial videos because it lags a lot. I think we should boost our internet link speed" (S3). Another issue mentioned by students is the limited screen size: "From my point of view, the primary benefit of mobile learning is that you can access lessons from any location and only learn at the point of need. However, you have to have mobile devices that sometimes cost a lot to be part of mobile learning, and the size of devices is so limited, which makes it difficult for those who use devices for a long period of time to focus on the displayed content" (S10). 


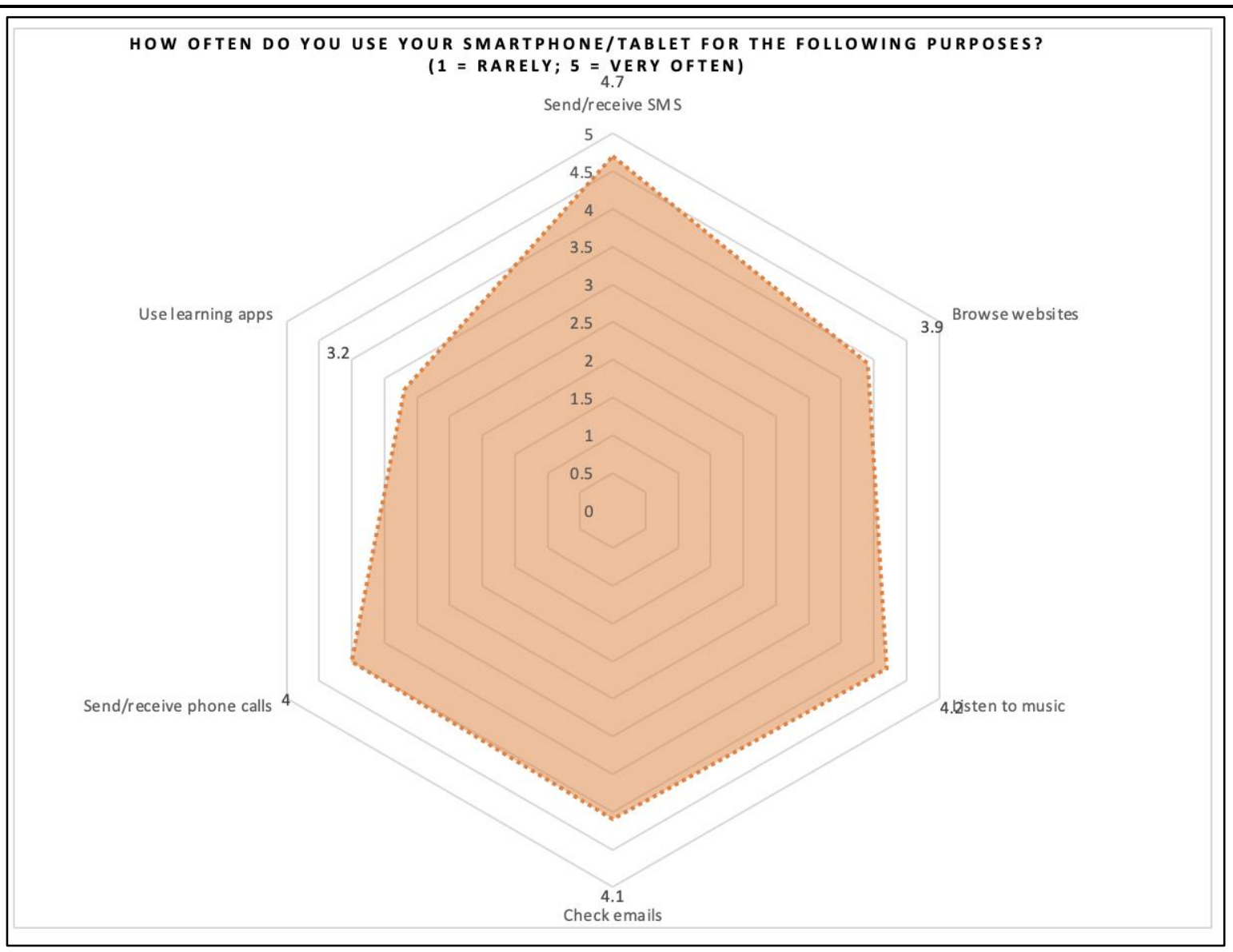

Chart 2: Frequency of using mobile devices for different purposes $(n=67)$

\subsection{Learning styles and habits}

The majority of students favored written knowledge to be accompanied by visual support in terms of learning styles (70,3\%). Most students decided that picturing it in their minds was the best way to recall anything $(85,6 \%)$. A large number of students favored learning resources such as speech, video and games with multimedia content. In the mobile training courses in which visual materials and interactive content were used a lot, these learning styles were very well supported. This was verified in the comments of these students: "The advantage I have for mobile learning is that when learning with videos, photos, etc. that attract me, I can learn more efficiently, not easily lose focus or feel sleepy" (S22). In addition, some students thought that mobile learning makes them better remember the lesson content better than reading text: "Images, videos, and voice help me better remember the lesson than texts. On the Internet, I can work with my groups effectively! I like to watch videos and pictures because it helps me remember knowledge longer than some dull textbooks, and I think it's the perfect way for me to learn foreign languages" (S19).

Most students were not so sure, however, whether they would benefit from online learning and online interaction. A reasonable number of students felt that quality learning could not take place without face-to-face contact (20,7\%). A few students did not feel comfortable interacting by writing with others $(\mathrm{n}=16,14,4 \%)$. Anyway, most students were willing to learn online on mobile devices. It is natural for them to have mixed feelings because almost all of these students have had so little experience with 
online learning on mobile devices before: "I haven't taken a mobile learning course before, so it seems too weird for me. But, via several channels, I've heard about it, and I'm really interested" (S32). While mobile learning can provide the style of learning that students need in physical education, many students feel that they are not ready for it: "I prefer visual, auditory and reflective styles, and there are those in mobile learning. I'm still not used to learning without face-to-face contact, though" (S8). Despite those challenges, most students were ready for mobile learning in teaching styles, taking into account their preference for interactive materials in the mobile learning framework.

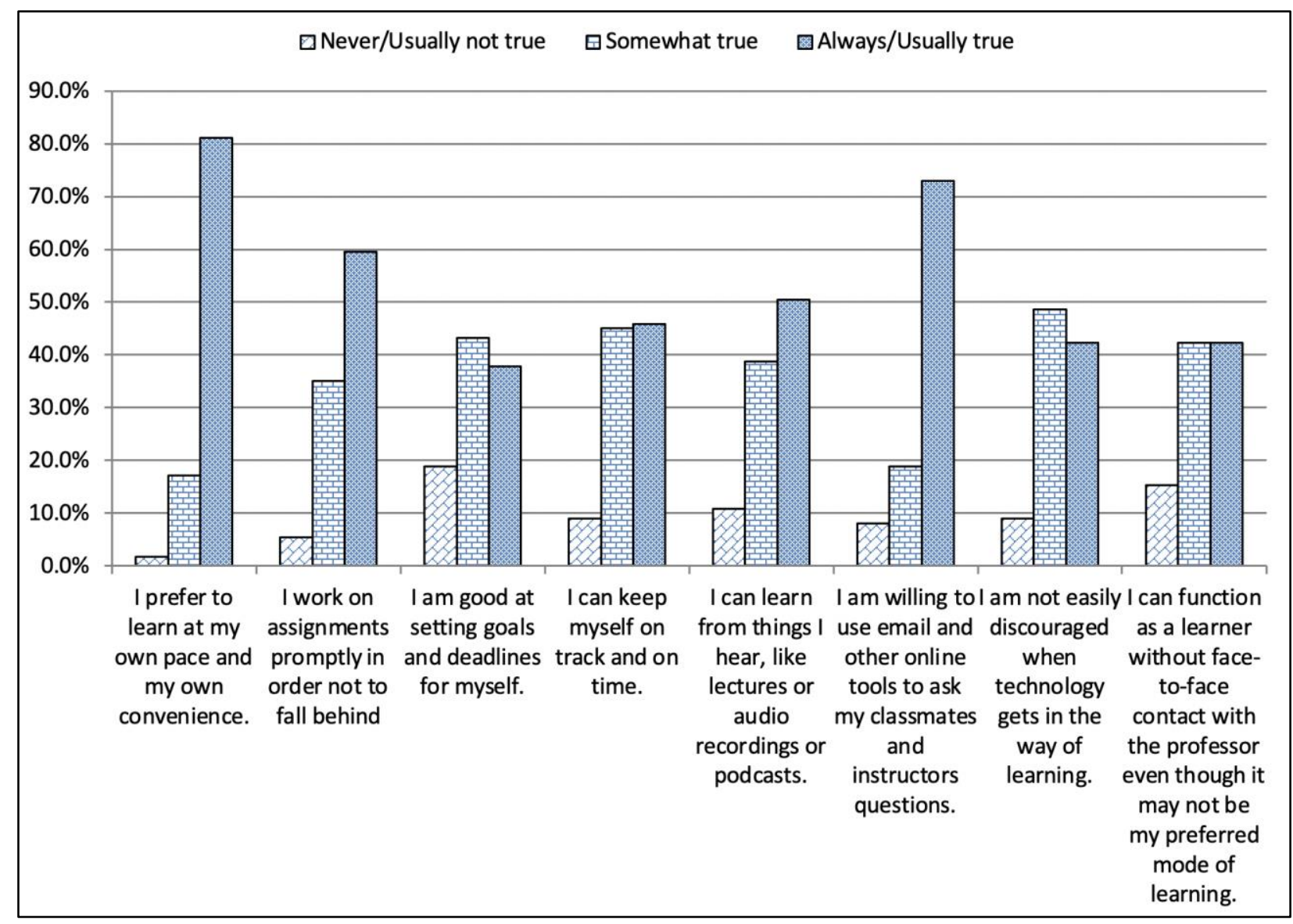

Chart 3: Students' habits when learning in the mobile learning system

As for learning habits, $81 \%$ of the respondents claim that they prefer to learn at their own pace and their own convenience. Similarly, $73,2 \%$ of the surveyed students said that they were willing to use email and other online tools to ask their classmates and instructors questions. Nearly half of the students agreed that they were not easily discouraged when technology got in the way of learning. A similar result (50,5\%) applies to whether students could learn from things they heard like lectures or audio recordings or podcasts. To be short, the data from chart 3 show that the majority of the students participating in the survey have high learner autonomy and they are ready for online learning. 


\subsection{Log data results}

The logs from the server of the m-learning system were also analyzed, and those logs were compared to the survey results. To decide if the m-learning course was effective in inspiring students to devote more time and energy toward learning, a dedication tool was used to gather data in order to determine if the course was a success. The learning time is measured based on the amount of time spent in learning sessions and the time spent in each session. How long each person uses the mobile learning system for their training outside the class was taken into consideration in order to calculate the overall learning commitment:

1) Click: Every time a user loads a page in the system, a log entry is stored into the database.

2) Session duration: The amount of time elapsed between the first and last click of a session.

Table 1: Top 20 dedicated students in the mobile learning system

\begin{tabular}{|c|c|c|c|}
\hline Student & Course dedication (mins) & Course dedication & Connections per day \\
\hline 1 & 3529 & 58 hours 49 mins & 0.24 \\
\hline 2 & 2465 & 41 hours 4 mins & 0.23 \\
\hline 3 & 2196 & 36 hours 35 mins & 0.24 \\
\hline 4 & 2195 & 36 hours 35 mins & 0.15 \\
\hline 5 & 2180 & 36 hours 20 mins & 0.22 \\
\hline 6 & 2157 & 35 hours 56 mins & 0.18 \\
\hline 7 & 2061 & 34 hours 21 mins & 0.18 \\
\hline 8 & 2058 & 34 hours 17 mins & 0.29 \\
\hline 9 & 1878 & 31 hours 17 mins & 0.18 \\
\hline 10 & 1851 & 30 hours 51 mins & 0.16 \\
\hline 11 & 1834 & 30 hours 33 mins & 0.15 \\
\hline 12 & 1735 & 28 hours 55 mins & 0.15 \\
\hline 13 & 1639 & 27 hours 18 mins & 0.14 \\
\hline 14 & 1613 & 26 hours 52 mins & 0.21 \\
\hline 15 & 1597 & 26 hours 37 mins & 0.19 \\
\hline 16 & 1577 & 26 hours 17 mins & 0.2 \\
\hline 17 & 1540 & 25 hours 40 mins & 0.18 \\
\hline 18 & 1527 & 25 hours 27 mins & 0.16 \\
\hline 19 & 1506 & 25 hours 5 mins & 0.2 \\
\hline 20 & 1495 & 24 hours 55 mins & 0.16 \\
\hline
\end{tabular}

Learning dedication from the log data in Table 1 shows that students did spend a lot of time working with the learning contents within the course, with the most dedicated student spending 48 hours 49 mins and the least dedicated student spending 24 hours 55 mins. The average time every student in the course spent on course materials was 13 hours 15 mins. Comparing with the total time for face to face meetings of 30 class periods (1500 mins in total), the average amount of time each student worked with the course materials was significant in the teaching context of Vietnam. As data from table 2 shows, a lot of students worked really hard in the system. In other words, the mobile learning 
system was able to motivate students' interest in the learning activities. This is an important factor in enhancing students' overall performance in the course.

\section{Conclusion}

The results from this paper suggest that, even though most students have no experience with it, mobile learning has a lot of potential for physical education training. The majority of students have sufficient access to the Internet and have mobile devices readily accessible. Although there are a few needed changes, most students can easily change and display a digital-friendly learning style. The results of this study reflect previous findings regarding online learning styles (Belfi et al., 2015; Best \& MacGregor, 2017; Nguyen et al., 2019). Despite the high levels of satisfaction that the participants in this study had, many students in the class also had a desire to learn with their peers and in a more familiar manner, such as in personal classroom discussions and group work with face to face interaction; something that e-learning seems to fail to deliver. Poor computer skills can make it difficult for students to learn online successfully. To better assist students in accessing the Internet, it is recommended that we strengthen our infrastructure around internet access. Besides, preparation for online learning should be recommended for physical education students.

\section{Conflict of Interest Statement}

Nguyen The Luong, Nguyen Ngoc Vu, and Nguyen Thi Hong Lien declare that they have no conflict of interest.

\section{About the Authors}

Nguyen The Luong is a lecturer at HCMC University of Physical Education \& Sports. He is the author of various articles on ICT in physical education, especially badminton training, and has related in numerous workshops on online learning.

Nguyen Ngoc $\mathbf{V u}$ is an Associate Professor at the Faculty of Social Sciences and Foreign Languages, Hoa Sen University, Vietnam with 15 years of experience building and consulting ICT integration into education and digital transformation in Vietnam. He won Vietnam Technology Innovation Award in 2012 and got recognized as Microsoft Innovative Educator (MIE) Master Trainer in 2014. His research interests include Computer Assisted Language Learning, Cognitive Linguistics, Educational Technology, and ELT Methodology.

Nguyen Thi Hong Lien is a lecturer at the Faculty of Social Sciences and Foreign Languages, Hoa Sen University, Vietnam. Her research interests include English for Special Purposes, Educational Technology, and Business Administration. 


\section{References}

Belfi, L. M., Bartolotta, R. J., Giambrone, A. E., Davi, C., \& Min, R. J. (2015). “Flipping” The Introductory Clerkship in Radiology: Impact on Medical Student Performance and Perceptions. Academic Radiology, 22(6), 794-801. https://doi.org/10.1016/j.acra.2014.11.003

Best, M., \& MacGregor, D. (2017). Transitioning Design and Technology Education from physical classrooms to virtual spaces: implications for pre-service teacher education. International Journal of Technology and Design Education, 27(2), 201-213. https://doi.org/10.1007/s10798-015-9350-z

Borba, M. C., Askar, P., Engelbrecht, J., Gadanidis, G., Llinares, S., \& Aguilar, M. S. (2016). Blended learning, e-learning and mobile learning in mathematics education. ZDM - Mathematics Education, 48(5), 589-610. https://doi.org/10.1007/s11858-016-0798-4

Chao, C. M. (2019). Factors determining the behavioral intention to use mobile learning: An application and extension of the UTAUT model. Frontiers in Psychology, 10(JULY). https://doi.org/10.3389/fpsyg.2019.01652

Doumanis, I., Economou, D., Sim, G. R., \& Porter, S. (2019). The impact of multimodal collaborative virtual environments on learning: A gamified online debate. Computers and Education, 130, 121-138. https://doi.org/10.1016/j.compedu.2018.09.017

Feng, J., Zhang, M., Wang, H., Yang, Z., Zhang, C., Li, Y., \& Jin, D. (2019). DPlink: User identity linkage via deep neural network from heterogeneous mobility data. The Web Conference 2019 - Proceedings of the World Wide Web Conference, WWW 2019, 459-469. https://doi.org/10.1145/3308558.3313424

Hung, B. P., Truong, V., \& Nguyen, N. V. (2018). Students' responses to CL-based teaching of english prepositions. Egitim Arastirmalari - Eurasian Journal of Educational Research, 2018(73), 41-58. https://doi.org/10.14689/ejer.2018.73.3

Huy, C. V., Luong, N. T., \& Vu, N. N. (2020). Blended learning in badminton training for professionals: students' perceptions and performance impacts. European Journal of Physical Education and Sport Science, 6(6), 28-36.

Langbeheim, E., \& Levy, S. T. (2019). Diving into the particle model: Examining the affordances of a single user participatory simulation. Computers and Education, 139, 65-80. https://doi.org/10.1016/j.compedu.2019.05.006

Linh, V. T., \& Vu, N. N. (2019). EFL learners' perceptions of blended learning in higher education. GloCALL 2019: Globalization and Localization in Computer-Assisted Language Learning.

Linh, V. T., \& Vu, N. N. (2021). The Impact of Mobile Learning on EFL Students' Learning Behaviors and Perceptions: From Content Delivery to Blended Interaction. International Research in Higher Education, 5(4), 25. https://doi.org/10.5430/irhe.v5n4p25

Manzoor, A. (2018). Blended learning in higher education: A developing country perspective. In Online Course Management: Concepts, Methodologies, Tools, and 
Applications (Vol. 3, pp. 1439-1449). https://doi.org/10.4018/978-1-5225-54721.ch075

Nguyen, D. M., Do, T. H., Calderbank, R., \& Deligiannis, N. (2019). Fake news detection using deep markov random fields. NAACL HLT 2019 - 2019 Conference of the North American Chapter of the Association for Computational Linguistics: Human Language Technologies - Proceedings of the Conference, 1, 1391-1400.

Retnaningrum, W. (2019). Instilling Character Education in Early Childhood by Using Illustrated Storybook. International Conference of Moslem Society, 3, 1-10. https://doi.org/10.24090/icms.2019.2481

Suartama, I. K., Setyosari, P., Sulthoni, \& Ulfa, S. (2019). Development of an instructional design model for mobile blended learning in higher education. International Journal of Emerging Technologies in Learning, 14(16), 4-22. https://doi.org/10.3991/ijet.v14i16.10633

Sun, Z., Liu, R., Luo, L., Wu, M., \& Shi, C. (2017). Exploring collaborative learning effect in blended learning environments. Journal of Computer Assisted Learning, 33(6), 575587. https://doi.org/10.1111/jcal.12201

$\mathrm{Vu}, \mathrm{N}$. N. (2016a). An investigation of Vietnamese students' learning styles in online language learning. Journal of Science, Ho Chi Minh University of Education, 79(1), 1624.

$\mathrm{Vu}$, N. N. (2016b). Mobile Learning in Language Teaching Context of Vietnam: an Evaluation of Students' Readiness. Journal of Science, HCMC University of Education, 7(85), 16-27. http://www.vjol.info/index.php/sphcm/article/viewFile/24861/21273

$\mathrm{Vu}$, N. N., Phuong, L. T. T., Lien, N. T. H., \& Luong, N. T. (2020). Using interactive whiteboard for teaching vocabulary to young English learners: Students' performance and perceptions. Journal of Critical Reviews, 7(19), 6651-6657.

$\mathrm{Vu}$, N. N., \& Thu, D. T. M. (2015). The use of Facebook group as an online educational tool in teaching writing to high school students. Journal of Foreign Language Studies, Hanoi University, 43.

Yusuf, Q., Yusuf, Y. Q., Erdiana, N., \& Pratama, A. R. (2018). Engaging with Edmodo to teach english writing of narrative texts to Eflstudents. Problems of Education in the 21st Century, 76(3), 333-349. 
Nguyen The Luong, Nguyen Ngoc Vu, Nguyen Thi Hong Lien

MOBILE LEARNING FOR PHYSICAL EDUCATION STUDENTS IN VIETNAM: PROMISES AND CHALLENGES

Creative Commons licensing terms

Authors will retain the copyright of their published articles agreeing that a Creative Commons Attribution 4.0 International License (CC BY 4.0) terms will be applied to their work. Under the terms of this license, no permission is required from the author(s) or publisher for members of the community to copy, distribute, transmit or adapt the article content, providing a proper, prominent and unambiguous attribution to the authors in a manner that makes clear that the materials are being reused under permission of a Creative Commons License. Views, opinions and conclusions expressed in this research article are views, opinions and conclusions of the author(s). Open Access Publishing Group and European Journal of Physical Education and Sport Science shall not be responsible or answerable for any loss, damage or liability caused in relation to/arising out of conflict of interests, copyright violations and inappropriate or inaccurate use of any kind content related or integrated on the research work. All the published works are meeting the Open Access Publishing requirements and can be freely accessed, shared, modified, distributed and used in educational, commercial and non-commercial purposes under a Creative Commons attribution 4.0 International License (CC BY 4.0). 